\title{
Does sinus rhythm conversion after cardiac surgery affect postoperative health- related quality of life?
}

Henrica N. A. M. van Breugel ${ }^{1 \dagger}$, Orlando Parise ${ }^{1 \dagger}$, Fred H. M. Nieman², Ryan E. Accord ${ }^{1}$, Fabiana Lucà', Pieter Lozekoot ${ }^{1}$, Narendra Kumar ${ }^{1}$, Ghislaine A. P. G. van Mastrigt ${ }^{1}$, Jan F. M. A. Nijs' ${ }^{1}$, Ries Vrakking ${ }^{3}$, Jos G. Maessen ${ }^{1}$, Mark La Meir ${ }^{1}$ and Sandro Gelsomino ${ }^{1,4^{*}}$

\begin{abstract}
Background: We investigated the impact and the predictive value of sinus rhythm at 12 months $\left(\mathrm{SR}_{12}\right)$ on subscales of three different HrQoL questionnaires: SF-36., EuroQoL and MFI 20.

Methods: Data of 125 cardiac surgery patients with pre-operative AF from our previous randomized trial were used. Based on their rhythm outcome patients were divided in two groups: $\mathrm{SR}_{12}$ or $\mathrm{AF}$ at 12 months follow up (non-SR ${ }_{12}$ ). All questionnaires were self-administered pre-operatively and at 3 months, 6 months and 12 months after surgery.

Results: Synus rhytm at 12 months was predictive of improvement of SF36- mental score (MS, $p=0.021$ ), Euro-QoL-MS $(p=0.009)$, VAS $(p=0.006)$, and MFI 20-MS $(p=0.009)$. We failed to find any significant interactions between $\mathrm{SR}_{12}$ and any of the other significant risk factors: age $<65$ years, paroxysmal type of AF and preoperative AF duration $<12$ months. In contrast, $\mathrm{SR}_{12}$ was not significant in predicting physical score (PS) subscales of any of the questionnaires (all, $p>0.05$ ) which were predicted by age $<65$ years (SF36-PS, $p=0.029$ ) by paroxysmal type of AF and age $<65$ years (Euro-QoL-PS, $p=0.017$ and $p=0.04$, respectively) and by AF duration $<12$ months, paroxysmal type of AF and age $<65$ years (MFI 20-PS, $p=0.019, p=0.020$ and $p=0.015$, respectively).
\end{abstract}

Conclusions: Specific mental-related HrQoL scales are much more sensitive to sinus rhythm conversion. Sinus rithm mantainance shows significant effects on mental scores independently of other cofactors. Successful conversion to sinus rhythm after surgical ablation during cardiac surgery does not significantly affect phisical health related quality of life during 1 year follow up.

Keywords: Atrial fibrillation, Health related quality of life, Ablation

\section{Background}

Atrial fibrillation (AF) is the most common cardiac rhythm disorder seen in the clinical practice accounting for approximately one-third of hospitalizations or cardiac rhythm disturbance [1].

Health-related quality of life (HrQoL) of patients with AF has been reported to significantly worsen, therefore

\footnotetext{
* Correspondence: sandro.gelsomino@libero.it

${ }^{\dagger}$ Equal contributors

${ }^{1}$ Department of Cardiology and Cardiothoracic Surgery, University Hospital of Maastricht, Maastricht, The Netherlands

${ }^{4}$ Experimental Surgery Unit, Careggi Hospital, Viale Morgagni 85, 50134 Florence, Italy

Full list of author information is available at the end of the article
}

enhancing HrQoL has gradually been established as one of the most important target when treating patients with AF [2]. Indeed, HrQoL has been shown to improve following medical theraphy and transcatheter ablation [3, 4]. In addition, it has beed demonstrated that conversion to sinus rhythm by surgical ablation during other cardiac surgery procedures (add-on surgery) can significantly improve the health-related quality of life $[5,6]$.

Nonetheless, concerns remain regarding whether this improvement in HrQoL is affected more by the treatment of the underlying heart disease than by the restoration of sinus rhythm (SR) since the relationship 
Table 1 Demographic Data $(n=125)$

\begin{tabular}{|c|c|c|c|c|}
\hline & Study population & SR12-group $(N=62)$ & Non-SR12-group $(N=63)$ & $p$-value \\
\hline Age (Years) & $67.9 \pm 8.9$ & $67.4(39.0-84.0)$ & $68.4(46.0-81.0)$ & .38 \\
\hline Weight (Kg) & $79.2 \pm 17.0$ & 78.6 (49-170) & $79.7(53-111)$ & .73 \\
\hline Gender (male) & $79(63.2 \%)$ & $42(66.7 \%)$ & $37(59.7 \%)$ & .42 \\
\hline Civil state & & & & .16 \\
\hline Divorced & $8(6.5 \%)$ & $7(11.1 \%)$ & $1(1.6 \%)$ & \\
\hline Married & $84(87.7 \%)$ & $42(66.7 \%)$ & $42(68.9 \%)$ & \\
\hline Unmarried with partner & $10(8.1 \%)$ & $5(7.9 \%)$ & $5(8.2 \%)$ & 0.16 \\
\hline Widow(er) & $22(17.7 \%)$ & $9(14.3 \%)$ & $13(21.3 \%)$ & \\
\hline \multicolumn{5}{|l|}{ Education } \\
\hline Primary school & $27(22.0 \%)$ & $11(17.5 \%)$ & $16(26.7 \%)$ & \\
\hline Lower education & $30(24.4 \%)$ & $15(23.8 \%)$ & $15(25.0 \%)$ & .52 \\
\hline Intermediate education & 45 (36.6 \%) & $24(38.1 \%)$ & $21(35.0 \%)$ & \\
\hline High education & $21(17.1 \%)$ & $13(20.6 \%)$ & $8(13.3 \%)$ & \\
\hline \multicolumn{5}{|l|}{ Previous cardiac history } \\
\hline \multicolumn{5}{|l|}{ Atrial Fibrillation: } \\
\hline Paroxysmal AF & $54(43.2 \%)$ & $37(58.7 \%)$ & $17(27.4 \%)$ & \\
\hline Permanent AF & $41(32.8 \%)$ & $11(17.5 \%)$ & $30(48.4 \%)$ & $<.01$ \\
\hline Persistent AF & $28(22.4 \%)$ & $13(20.6 \%)$ & $15(24.2 \%)$ & \\
\hline Atrial flutter & $2(1.6 \%)$ & $2(3.2 \%)$ & $0(0 \%)$ & \\
\hline Total months of AF & $82.0 \pm 104.8$ & $67.9(3-403)$ & $96.9(3-617)$ & .03 \\
\hline Left Atrial Dimension (mm) & $50.6 \pm 7.4$ & $48.7(33-65)$ & $53.3(40-70)$ & $<.01$ \\
\hline Left Ventrical Ejection Fraction (\%) & $52.6 \pm 13.5$ & $53.2(18-80)$ & $51.9(22-75)$ & .68 \\
\hline \multicolumn{5}{|l|}{ Co-morbidity/Riskfactors $(N=122)$} \\
\hline Hypertension & $51(41.8 \%)$ & $25(40.3 \%)$ & $26(43.3 \%)$ & .74 \\
\hline Stroke & $6(4.9 \%)$ & $2(3.2 \%)$ & $4(6.7 \%)$ & .38 \\
\hline Smoking: & & & & .50 \\
\hline Never & $56(46.3 \%)$ & $30(48.4 \%)$ & $26(44.1 \%)$ & \\
\hline Current & $16(13.2 \%)$ & $6(9.4 \%)$ & $10(16.9 \%)$ & \\
\hline Past & $49(40.5 \%)$ & $26(41.9 \%)$ & $23(39.0 \%)$ & \\
\hline Positive Family History & $61(49.2 \%)$ & $27(42.9 \%)$ & $34(55.7 \%)$ & .15 \\
\hline Diabetes & $18(14.8 \%)$ & $13(21.0 \%)$ & $5(8.3 \%)$ & .05 \\
\hline Renal Disease & $7(5.6 \%)$ & $3(4.8 \%)$ & $4(6.5 \%)$ & .68 \\
\hline COPD & $20(16.3 \%)$ & $8(12.7 \%)$ & $12(20.0 \%)$ & .27 \\
\hline Previous myocardial infarction & $31(24.8 \%)$ & $19(30.2 \%)$ & $12(19.4 \%)$ & .16 \\
\hline Cardiomyopathy & $21(17.1 \%)$ & $10(16.1 \%)$ & $11(18.0 \%)$ & .78 \\
\hline Congenital Heart disease & 7 (5.7 \%) & $2(3.2 \%)$ & $5(8.3 \%)$ & .22 \\
\hline Systolic Blood Pressure (mmHg) & $141.9 \pm 26.6$ & $144.7(70-200)$ & $139.3(80-190)$ & .28 \\
\hline Diastolic Blood Pressure (mmHg) & $79.4 \pm 17.8$ & $82.3(40-180)$ & $76.5(40-110)$ & .18 \\
\hline \multicolumn{5}{|l|}{ Pre-operative complaints $(N=123)$} \\
\hline Palpitations & $51(41.5 \%)$ & $28(45.2 \%)$ & $23(37.7 \%)$ & .40 \\
\hline Dyspnea & $98(79.7 \%)$ & $48(77.4 \%)$ & $50(82.0 \%)$ & .53 \\
\hline Angina & $49(40.2 \%)$ & $24(39.3 \%)$ & $25(41.0 \%)$ & .85 \\
\hline (Pre-) Syncope & $7(5.7 \%)$ & $3(4.8 \%)$ & $4(6.6 \%)$ & .68 \\
\hline
\end{tabular}


Table 1 Demographic Data $(n=125)$ (Continued)

\begin{tabular}{|c|c|c|c|c|}
\hline Dizziness & $32(26.0 \%)$ & $17(27.4 \%)$ & $15(24.6 \%)$ & .72 \\
\hline Fatigue & $62(50.4 \%)$ & $31(50.0 \%)$ & $31(50.8 \%)$ & .93 \\
\hline Other complaints & $12(9.8 \%)$ & $5(8.1 \%)$ & $7(11.7 \%)$ & .50 \\
\hline \multicolumn{5}{|l|}{ Operative data $(N=125)$} \\
\hline Coronary Artery Bypass Grafting & $39(31.2 \%)$ & $23(36.5 \%)$ & $16(25.8 \%)$ & \\
\hline Valve replacement & $50(40.0 \%)$ & $24(38.1 \%)$ & 26 (41.9\%) & .11 \\
\hline CABG and Valve replacement & $28(22.4 \%)$ & $15(23.8 \%)$ & $13(21.0 \%)$ & \\
\hline Other cardio-surgery & $8(6.4 \%)$ & $1(1.6 \%)$ & $7(11.3 \%)$ & \\
\hline
\end{tabular}

Abbreviations: SR Sinus Rhythm, AF Atrial Fibrillation, COPD Chronic obstructive pulmonary disease, CABG Coronary artery bypass graft

between conversion to SR and HrQoL has not been rigorously tested.

Therefore the present study was aimed at investigating the relationship between successful SR conversion and 1-year postoperative HrQoL after add-on surgery measuring the impact and the predictive value of $\mathrm{SR}_{12}$ on subscales of three different HrQoL questionnaires: SF36., EuroQoL and MFI 20.

\section{Methods}

\section{Study population}

Pre- and postoperative clinical data were used from the patients enrolled in the ASAF trial [7]. Based on their rhythm outcome patients were divided in two groups: $\mathrm{SR}$ at 12 months follow up $\left(\mathrm{SR}_{12}\right)$ or $\mathrm{AF}$ at 12 months follow up (non-SR ${ }_{12}$ ). Antiarrhythmic and anticoagulant protocols were as previously reported [7]. Patients were seen at the outpatient clinic 3 months, 6 months, and 12 months after the surgical procedure, and annually thereafter. All subjects reached 12-month follow-up. At each follow-up visit, patients underwent an electrocardiogram and, at the 12-month appointment, all patients had a 24-h Holter.

\section{Quality of life questionnaires}

For HrQoL assessment both generic- and diseasespecific questionnaires were used.

The RAND 36-item Health Survey 1.0 (SF-36) displays 8 multi-item scales (Body Pain, BP; General Health, GH, Mental Health, MH; Phisical Functioning PF; Role Emotional, RE, Role Phisical,RP; Social Functioning, SF; Vitality Vt). Each domain comprises a 5point Likert scale ranging from 1 (bad perceived health) to 5 (excellent perceived health) [8]. SF-36 also assesses 2 major health concepts, physical and mental, with 2 composite scores, the physical composite score (PCS) and the mental composite score (MCS). The physical scales (Physical Functioning, Role Physical, Bodily Pain, and General Health) make up the PCS, and the remaining 4 scales (Mental
Health, Role Emotional, Vitality, and Social Functioning) make up the MCS. Reliability by the test-retest6 between baseline and at follow-up was good, with interclass correlation coefficients ranging between 0.75 and 0.88. Internal consistency [9] was good for the 8 scales, with Cronbach coefficients ranging between 0.86 and 0.93 .

The EuroQoL is a self-report questionnaire that consists of 2 parts- EQ-VAS (visual analogue scale of 0 to 100 for recording an individuals' rating of their current health-related QoL state), and the three-level, fivedimensional descriptive system (EQ-5D), which evaluates mobility (M), self-care (SC), usual activities (UA), pain/discomfort (P/D) and anxiety/depression (A/D) on a 0 to 100 scale using the European value set [10].

The Multidimensional Fatigue Inventory (MFI-20) consists of 5 scales of fatigue (General Fatigue, GF; Mental Fatigue, MF; Phisical Fatigue, MF; Reduced Activities, RA, Reduced Motivation, RM) with scores ranging from 'definitely tired' to 'definitely not tired' on a 5-point Likert scale [11].

All questionnaires were self-administered preoperatively and at 3 months, 6 months and 12 months after surgery.

\section{Statistical analysis}

The power analysis was determined by Graph Pad Stat Mate software, release 2.00 (Graph Pad Prism Software, Inc, San Diego, CA) on the basis of the following assumption: type I error of 0.05 (two-sided) and difference in 12-month SF-36-mental health of 3.4. The calculated statistical power was 0.85 with a sample size per group of 62 . Continuous data were expressed as mean \pm standard deviation, frequence as percentage and non-normally distributed data as median and interquartile range (IQR). Data were compared for statistical significance using $t$-test, $X^{2}$ or Mann-Whitney tests as appropriate. Multiple comparisons of HrQoL scores over time were carried by ANOVA with Friedmann test. 
A generalized linear model (GLM) was employed to study the the effect of conversion to SR at 12 months as well as other categorical predictors (factors) or continuous predictors (covariates) on HrQoL. More specifically, six composite HrQoL outcomes were defined : the two
SF-36 composite scores (PCS and MCS), the VAS score, two EuroQoL composite scores (one mental score [EuroQoL-MS] including anxiety/depression and selfcare and one physical [EuroQoL-MS] with mobility, usual activities and pain/discomfort) and two MFI20

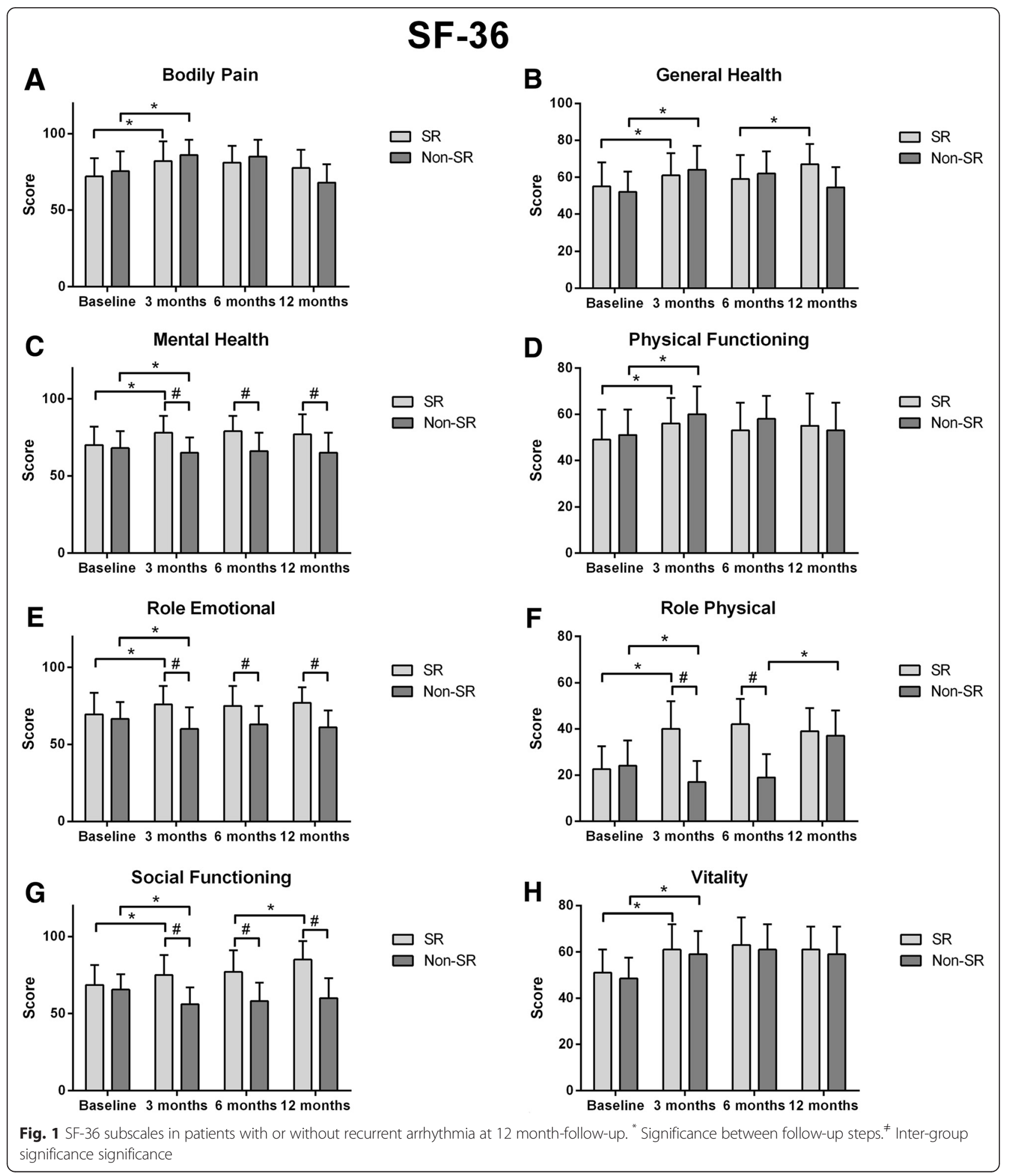


composite scores (one mental score [MFI20-MS] including Mental Fatigue and Reduced Motivation and one physical [MFI 20-PS] with General Fatigue, Phisical Fatigue, and Reduced Activities).

All these outcomes showed a skewed distribution using histograms paneled by single outcome. The following variables were entered as potential predictors into the model: preoperative (age, gender, type of AF, AF duration, left atrial dimension, left ventricular ejection fraction, myocardial infarction,hypertension, diabetes, renal disease, chronic obstructive pulmonary disease, renal insufficiency) intraoperative (coronary artery bypass grafting, valve replacement, associated intervention,other cardiac surgery) and postoperative $\left(\mathrm{SR}_{\mathrm{D}}, \mathrm{SR}_{3}, \mathrm{SR}_{6}, \mathrm{SR}_{12}\right)$. On the basis of our previous experience [7] we created four new categorical variables $(0 / 1)$ in the dataset: female sex, age $\geq 65$ years, AF duration $\geq 12$ months and type of $\mathrm{AF}>$ paroxysmal. We choosed a $\gamma$ distribution with a log-link function on the basis of the best goodness-of-fit and the type III analysis. The Wald $\chi^{2}$, the $\exp (\beta)$-Odd ration and the $95 \%$ Wald confidence for $\exp (\beta)$ were reported.

SPSS v.18.0 (IBM Corp., Armonk, NY, USA) was used for analysis and a $p$ value $<0.05$ was considered to indicate statistical significance.

\section{Results}

\section{Patient characteristics and rhythm follow up}

Seven patients died during the 12 months follow up therefore a total of 125 patients were taken into account for analysis. Among them, sixty-two (47 \%) were in SR sinus rhythm at 12 months follow up whereas 63 (53\%) had recurrent arrhythmia. Table 1 dysplays patients characteristics. Subjects who were not in SR at 12 months had larger atria $(p<0.001)$ and an higher perentage of patients with permanent AF $(<0.001)$. No other difference was detected between groups.

\section{Morbidity and mortality}

No significant differences were found between SR-group and non-SR-group regarding the number of rethoracotomies $(p=0.56)$, pulmonary complications $(p=0.07)$, myocardial infarction $(p=0.23)$, renal failure $(p=0.84)$, stroke $(p=0.38)$, wound infections and other infections $(p>0.9)$, hours of ICU stay $(p=0.09)$ and total hospital stay in days $(p=0.11)$.

\section{Effect of Add-on surgery on HrQoL SF-36}

Figure 1 shows the comparison in SF-36 domains between patients with or without AF at different times. At baseline SF-36 scores were comparable between Groups. All subscales of SF-36 improved at 3 months in patients without arrhythmia. In contrast, in patient with recurrent arrhythmia $\mathrm{BP}, \mathrm{GH}, \mathrm{PF}$ an Vt which improved fronm baseline $(p<0.05), \mathrm{MH}, \mathrm{RE}, \mathrm{RF}$ and SF worsended from baseline (all, $p<0.01$ ). The latter domains were significantly lower in patient with recurrent $\operatorname{AF}(p<0.05)$. At 6 months no significant variation was detected in both groups in SF- scales with intergroup-differences in $\mathrm{MH}, \mathrm{RE}, \mathrm{RF}$ and SF remaining unchanged (all, $p<0.01$ ).

Finally, at 12 months, only SF and GH further Improved in patients in SR. In patients with AF Mental Health, RE and SF worse than in patients with no-AF. In contrast RP improved and was not significantly different compared to AF patients.

Finally Physical composite score was not significantlty different between groups whereas mental composite score was significantly higher in patients without AF recurrence (Fig. 2).

\section{EuroQoL}

Compared with baseline, EQ-5D and EQ-VAS improved significantly at 12 months either in patients with SR $(61.2 \pm 11.3$ vs. $74.0 \pm 12.8, p<0.001$ and $67.5 \pm 10.9$ vs. $71.0 \pm 12.0, p=0.004)$ or those with AF (61.3 \pm 10.7 vs. $71.0 \pm 12.3, p=0.003$ and $68.1 \pm 10.3$ vs. $72.0 \pm 11.4, p=$ $0.02)$ with no significance between Groups $(p=0.06$ and $p=0.79$ for EQ-5D and EQ-VAS, respectively.

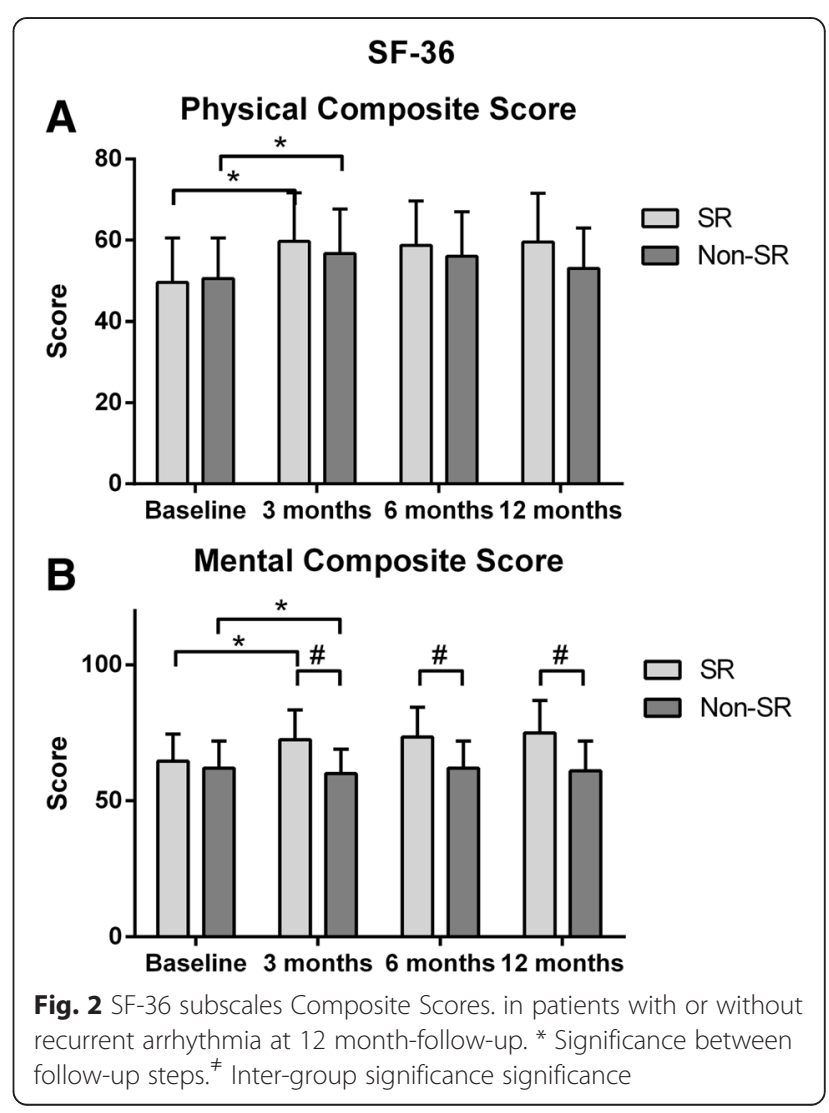


Table 2 Parameters estimates

\begin{tabular}{|c|c|c|c|c|}
\hline & Wald $x^{2}$ & $p$ & $\operatorname{Exp} \beta$ & $95 \% \mathrm{Cl} \operatorname{Exp} \beta$ \\
\hline \multicolumn{5}{|l|}{ SF $36-M S$} \\
\hline $\mathrm{SR}_{12}$ & 9.235 & 0.021 & 0.892 & $0.753-0.995$ \\
\hline Age $<65$ yrs & 7.818 & 0.018 & 1.211 & $1.098-1.431$ \\
\hline AF duration $<12$ months & 8.190 & 0.019 & 0.965 & $0.801-1.104$ \\
\hline \multicolumn{5}{|l|}{ SF 36 -PS } \\
\hline Age $<65$ yrs & 6.542 & 0.029 & 1.156 & $0.945-1.301$ \\
\hline \multicolumn{5}{|l|}{ Euro QoL-MS } \\
\hline $\mathrm{SR}_{12}$ & 8.221 & 0.009 & 0.788 & $0.589-0.873$ \\
\hline AF Paroxysmal & 10.234 & 0.005 & 1.167 & $0.902-1.298$ \\
\hline \multicolumn{5}{|l|}{ Euro QoL-PS } \\
\hline Age $<65$ yrs & 7.892 & 0.017 & 1.115 & $0.953-1.199$ \\
\hline AF Paroxysmal & 10.003 & 0.004 & 1.056 & $0.862-1.189$ \\
\hline \multicolumn{5}{|l|}{ Euro QoL-VAS } \\
\hline $\mathrm{SR}_{12}$ & 9.776 & 0.006 & 0.876 & $0.678-0.942$ \\
\hline AF Paroxysmal & 9.993 & 0.008 & 1.055 & $0.899-1.178$ \\
\hline \multicolumn{5}{|l|}{ MFI 20-MS } \\
\hline $\mathrm{SR}_{12}$ & 8.569 & 0.009 & 1.188 & $0.976-1.244$ \\
\hline Age $<65$ yrs & 7.908 & 0.016 & 1.045 & $0.932-1.177$ \\
\hline \multicolumn{5}{|l|}{ MFI 20-PS } \\
\hline Age $<65$ yrs & 9.044 & 0.019 & 1.266 & $1.088-1.399$ \\
\hline AF Paroxysmal & 9.302 & 0.020 & 0.877 & $0.745-0.978$ \\
\hline AF duration $<12$ months & 8.805 & 0.015 & 0.915 & $0.802-1.105$ \\
\hline
\end{tabular}

Abbeviations: Cl Confidence Interval, MS Mental Score, PS Physical Score, AF Atrial Fibrillation

Figure 3 shows that no difference was found in any EQ-5D sub-domains at 3, 6 or 12 months.

\section{MFI-20}

At 3 months, changes in GF, PF and RA were not significant in both group with any difference detected between patients with or without AF recurrence (Fig. 4). In contrast, in patients no in sinus rhythm MF and RM were significantly lower compared to baseline $(p=0.004)$ and to no-AF patients $(p<0.001)$. At 6 months and 12 months MF and RM did not improve in patient with $\mathrm{AF}$ and both these domains were significantly higher than SR patients $(p<0.001$ at 6 and 12 months). No other relevant changes were detected in patients in SR at 6 and 12 months.

\section{Relationship between 12-month SR and HrQoL}

Results of GLM are shown in Table 2. Synus rhytm at 12 months was independent predictor of SF36-MS. Age $<65$ years and preoperative AF duration <12 months were also significant. $\mathrm{SR}_{12}$ also predicted Euro-QoL-MS (with paroxysmal type of AF), VAS and MFI 20-MS.
In contrast, $\mathrm{SR}_{12}$ was not significant for SF36-PS, Euro-QoL-PS and MFI20 -MS (all, $p>0.05$ ).

On the contrary SF36-PS was predicted by age $<65$ years, Euro-QoL-PS by age $<65$ years and paroxysmal type of AF whereas MFI 20-PS by age < 65 years, paroxysmal type of $\mathrm{AF}$ and preoperative AF duration $<12$ months. $\mathrm{SR}_{3}$ and $\mathrm{SR}_{6}$ resulted to be not significant.

The subanalysis of the influence of $\mathrm{SR}_{12}$ according to the presence -absence of other cofactors showed that patients in SR at 12 months were associated with increased HrQoL regardless of age, preoperative AF durationand type of AF. There were no apparent significant interactions between $\mathrm{SR}_{12}$ and any of the covariates (Fig. 5).

\section{Discussion}

At the best of our knowledge, this is the first study to explore the relationship between manteinance of sinus rhythm 12 months after surgical ablation $\left(\mathrm{SR}_{12}\right)$ associated to other cardiac procedures (add-on surgery) and health-related quality of life (HrQoL). The purpose of the present report was to measure the impact and the predictive value of $\mathrm{SR}_{12}$ on subscales of three different HrQoL questionnaires: SF-36, EuroQoL and MFI 20.

The main findings of our study can be summarized as follows: First, sinus rhythm at 12 months was predictive of improvement of SF36-MS, Euro-QoL-MS, VAS and MFI 20-MS. Furthermore, when we allowed for interaction between type $\mathrm{SR}_{12}$ and other significant risk factors (age <65 years, paroxysmal type of AF and preoperative AF duration $<12$ months) we found that the effect of $\mathrm{SR}_{12}$ on SF36-MS, Euro-QoL-MS, VAS and MFI 20-MS was similar or even higher in low- versus high-risk- patients. Moreover, we failed to find any significant interactions between $\mathrm{SR}_{12}$ and any of the other risk factors demonstrating that $\mathrm{SR}_{12}$ remains a critical determinant of these HrQoL outcomes beyond any other potentially associated predictor.

It has been demonstrated that the impact of AF on HrQoL extends beyond symptoms. Indeed, the psychological and emotional effects of AF can be debilitating and several limited studies suggest that psychological distress may be linked with patient-reported AF symptom severity [12] and that patients with AF have a high prevalence of anxiety and depression [13, 14]. Furthermore, symptoms of depression and anxiety have been shown to be strong predictor of worsened quality of life $[15,16]$ and worsened outcomes [17-20] in patients with AF. However, there are limited data on the association fo SR manteinance and psychological status. Our study demonstrated the important influence of SR on HrQoL-mental scores regardless of which specific scale was used. In other words,in case of recurrent AF after 


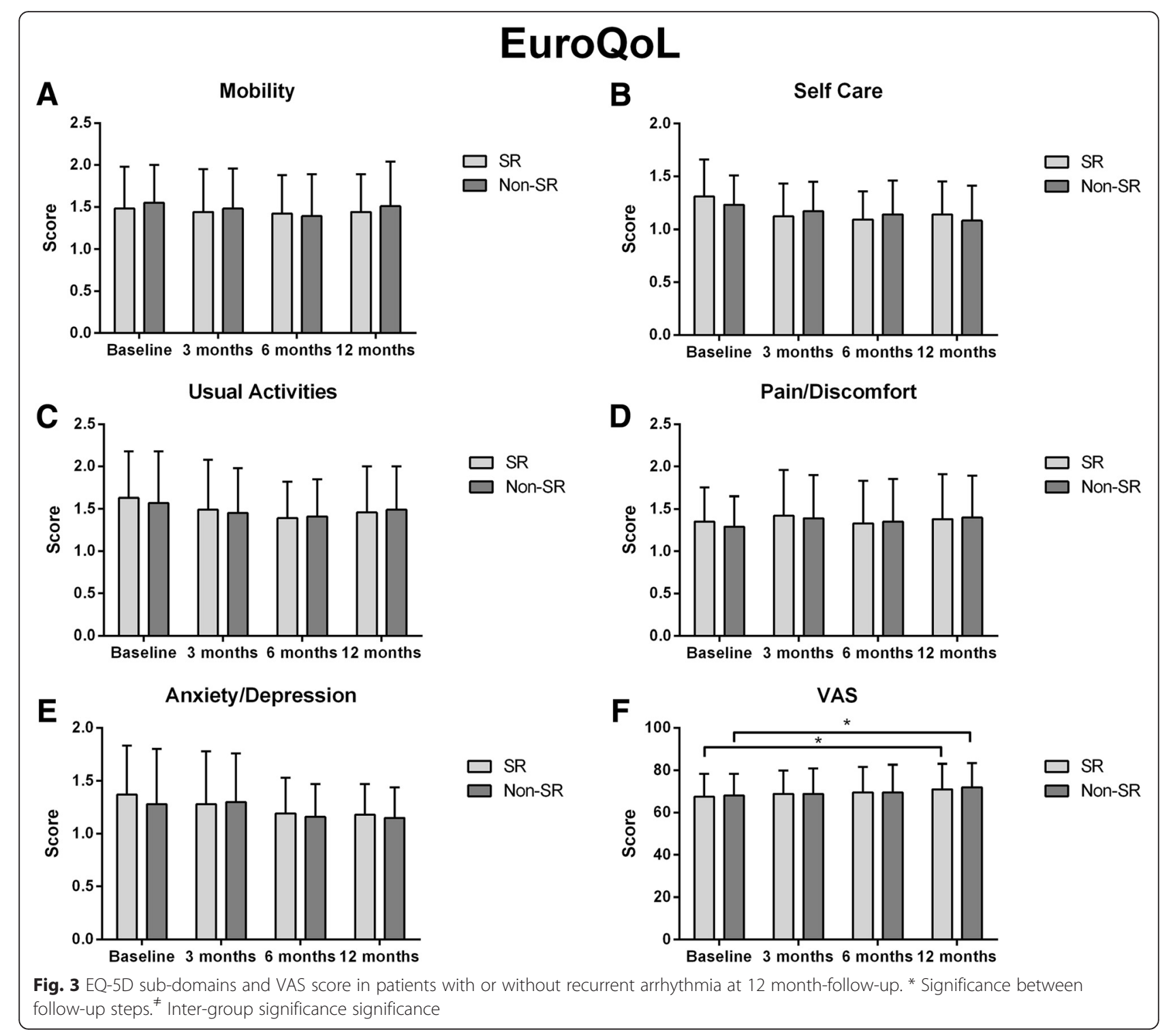

surgery, psychological comorbidities may heavily influence healthcare consumption. This aspect warrants further larger studies.

Second, $\mathrm{SR}_{12}$ was not significant in predicting SF36PS, Euro-QoL-PS and MFI20 -PS (all, $p>0.05$ ).

Our findings are in accordance with data from a recent reasearch [21] showing that patients who maintained sinus rhythm after ablation had a significant improvement in AF symptoms and $\mathrm{HrQoL}$ whereas no improvement was observed in patients with recurrent AF.

Prior studies for largely paroxysmal AF treated with catheter ablation showed a significant post-ablation amelioration of $\mathrm{HrQoL}$, with the benefit lasting over 2 years [22, 23]. Furthermore, Fiala et al [24] found a significant rise in QoL after catheter ablation of long- standing persistent AF at 1 year that further slightly increased at 2 years. Nonetheless, these authors, unlike for functional benefits, were not able to demonstrate a significant difference between SR and non-SR subgroups at 1 year when modest $\mathrm{HrQoL}$ improvement was also present in patients examined in AF/AT.

Third, in our experience SF36-PS was predicted by age $<65$ years, Euro-QoL-PS by age $<65$ years and paroxysmal type of AF whereas MFI 20-PS by age $<65$ years, paroxysmal type of $\mathrm{AF}$ and preoperative $\mathrm{AF}$ duration $<12$ months.

It is not surprising that patients with AF > paroxysmal show worse physical HrQoL subscales but it is interesting that $\mathrm{SR}_{12}$ was not predictive of pysical improvement despite patients in AFat 12 months a significantly higher percentage of pemanent AF patients (48.4\% vs. $17.5 \%)$. 


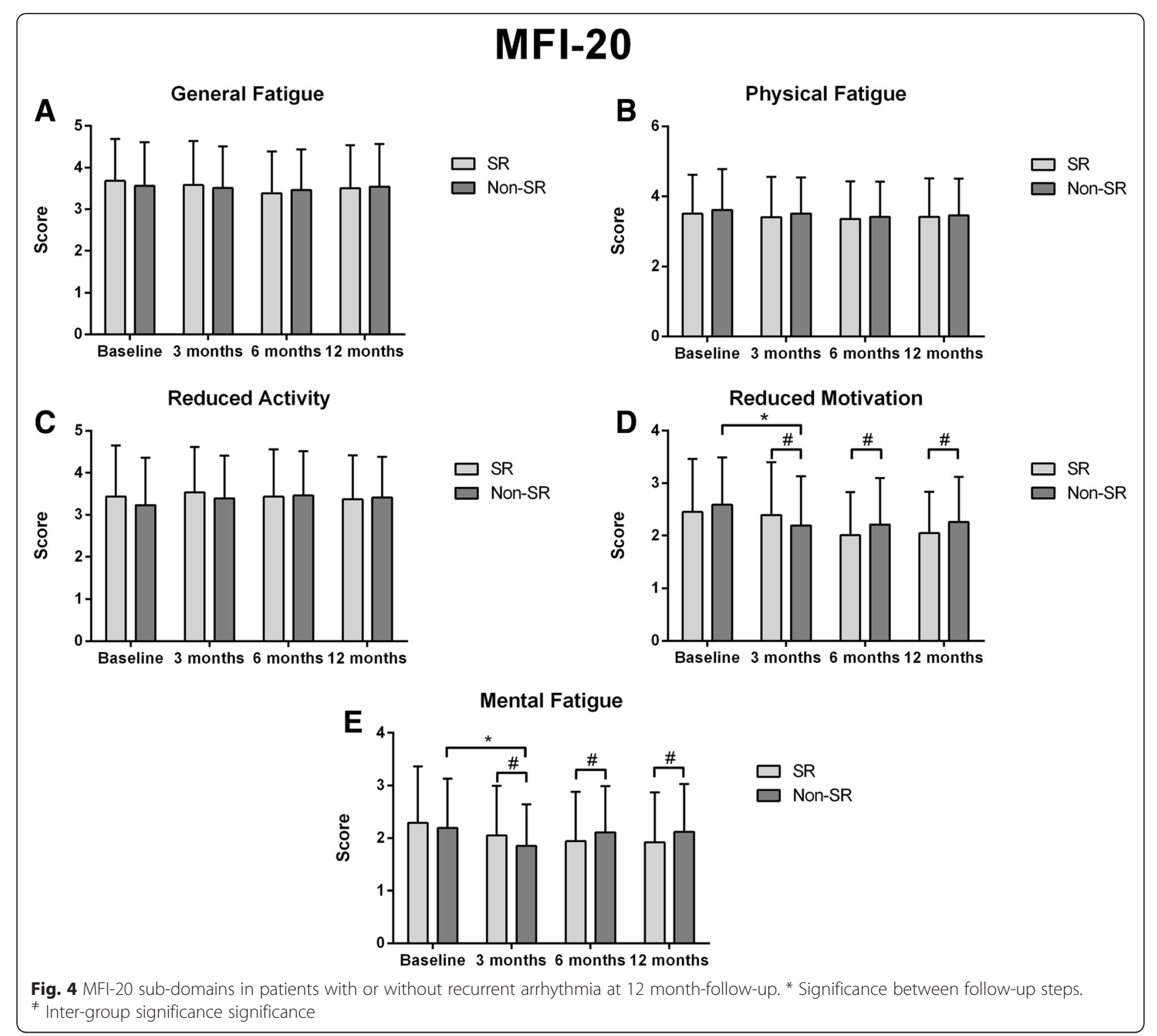

This suggest that the AF type is a primary predictor and it is not strenghten by the postoperative rhytm. This was confirmed by the not significant interaction between the two variables $(p=0.44)$.

Regarding age,as we might expect, $\geq 65$ years showed a worse HrQoL after surgery. However, it must be considered that elderly patients differ considerably from patients in the younger age group as they have a higher incidence of AF associated with other risk factors and frequent multiple comorbidities which may affect their pst-surgery HrQoL. Nonetheless, we do believe that there is no reason to deny a priory add- on surgery to elderly since results from the literature suggest that catheter ablation of AF in elderly patients can be performed with success rates comparable to those in younger without an increase in complication rate [25].

\section{Study limitations}

Our study has some limitations which need to be highlithed.

First of all, this study was performed retrospectively and this could have significantly affected our results. Second,we employed an old version and no disease specific-HrQoL questionnaires. It is well known that HrQoL outcomes can be weakened by other life events or physical complaints during follow up. This 'attenuation' effect may become even larger as the follow up period extends. 


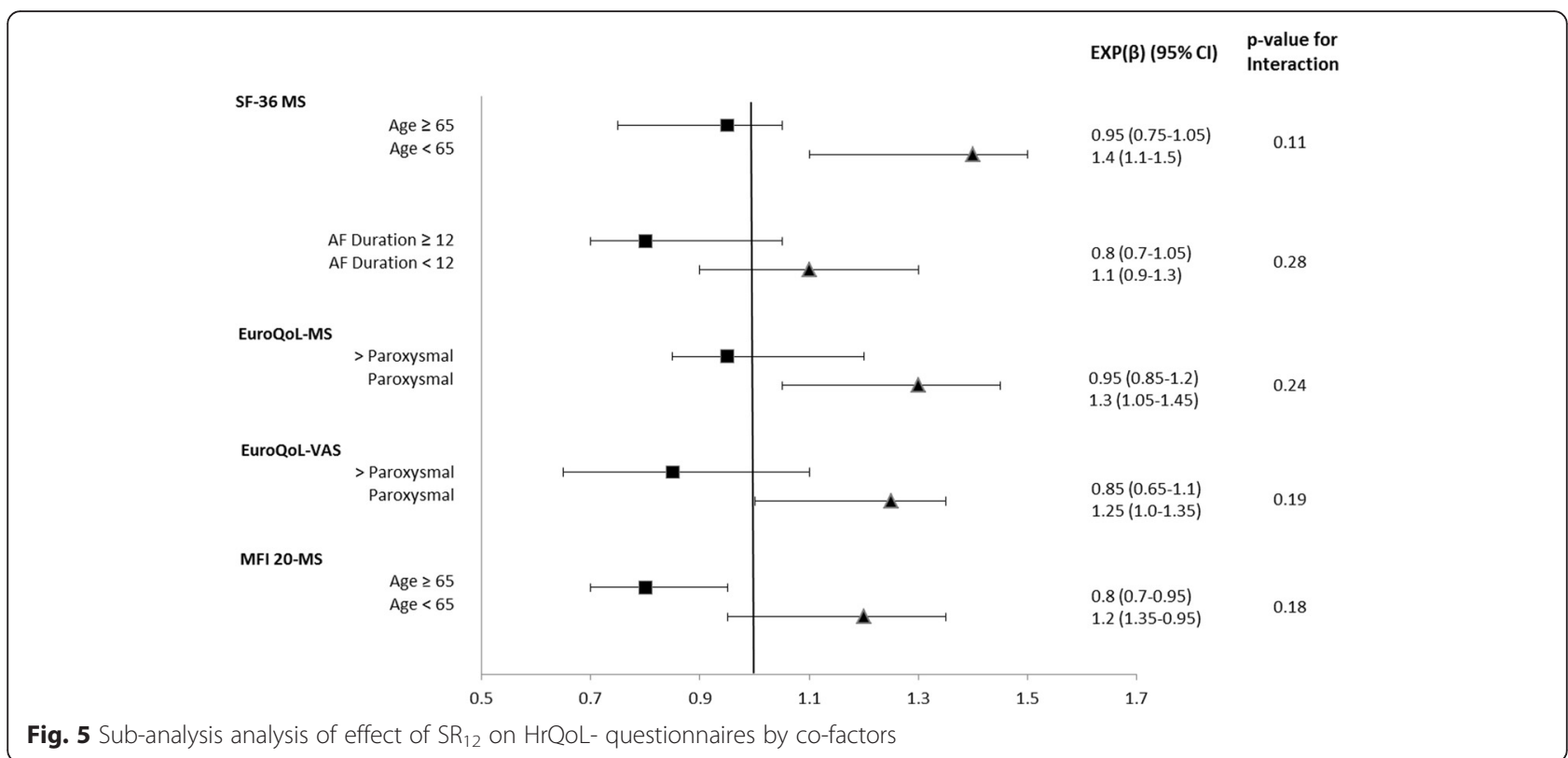

\section{Conclusions}

Specific mental-related HrQoL scales are much more sensitive to sinus rhythm conversion. Sinus rithm mantainance shows significant effects on mental scores independently of cofactors such as age, type of AF and AF type. Successful conversion to sinus rhythm after surgical ablation during cardiac surgery does not significantly affect phisical health related quality of life during 1 year follow up.

\section{Competing interests}

The authors declare that they have no competing interests.

\section{Authors' contributions}

HvB conception and design of the study and manuscript drafting. OP carried out data analysis. FN partecipated to conception and design of the manuscript. FL carried out data collection. PL carried out data collection. NK carried out data collection. GVM Partecipated to the drafting of the manuscript. JN contributed to data analysis. RV contributed to data analysis. JM carried out the revision of the manuscript for important contents. MLM carried out the revision of the manuscript for important contents. SG carried out the final revision and approval of the manuscript.

\section{Acknowledgments}

We gratefully acknowledge Dr Judith Wilson for the English revision of the paper.

\section{Disclosures}

None

\section{Author details}

${ }^{1}$ Department of Cardiology and Cardiothoracic Surgery, University Hospital of Maastricht, Maastricht, The Netherlands. ${ }^{2}$ Department of Clinical Epidemiology \& Medical Technology Assessment, University Hospital of Maastricht, Maastricht, The Netherlands. ${ }^{3}$ Department of Cardiothoracic Surgery, Amphia Hospital Breda, Maastricht, The Netherlands. ${ }^{4}$ Experimental Surgery Unit, Careggi Hospital, Viale Morgagni 85, 50134 Florence, Italy.

Received: 23 March 2015 Accepted: 5 April 2016

Published online: 03 May 2016

\section{References}

1. Kannel WB, Abbott RD, Savage DD, McNamara PM. Epidemiologic features of chronic atrial fibrillation. The Framingham study. N Engl J Med. 1982;306(17):1018-22.

2. Luderitz B, Jung W. Quality of life in patients with atrial fibrillation. Arch Intern Med. 2000;160:1749-57.

3. Dorian P, Mangat I. Quality of life variables in the selection of rate versus rhythm control in patients with atrial fibrillation: observations from the Canadian Trial of Atrial Fibrillation. Card Electrophysiol Rev. 2003;7(3):276-9.

4. Bubien RS, Knotts-Dolson SM, Plumb VJ, Kay GN. Effect of radiofrequency catheter ablation on health-related quality of life and activities of daily living in patients with recurrent arrhythmias. Circulation. 1996;94(7):1585-91.

5. Forlani S, De Paulis R, Guerrieri Wolf L, Greco R, Polisca P, Moscarelli M, et al. Conversion to sinus rhythm by ablation improves quality of life in patients submitted to mitral valve surgery. Ann Thorac Surg. 2006;81(3):863-7.

6. Lundberg C, Albåge A, Carnlöf C, Kennebäck G. Long-term health-related quality of life after maze surgery for atrial fibrillation. Ann Thorac Surg. 2008;86(6):1878-82.

7. Van Breugel HN, Nieman FH, Accord RE, Van Mastrigt GA, Nijs JF, Severens JL, et al. A prospective randomized multicenter comparison on health-related quality of life: the value of add-on arrhythmia surgery in patients with paroxysmal, permanent or persistent atrial fibrillation undergoing valvular and/ or coronary bypass surgery. J Cardiovasc Electrophysiol. 2010;21(5):511-20.

8. McHorney CA, Ware Jr JE, Raczek AE. The MOS 36-Item Short-Form Health Survey (SF-36): II. Psychometric and clinical tests of validity in measuring physical and mental health constructs. Med Care. 1993;31:247-63.

9. Ware JE, Snow KK, Kosinski M, Gandek B. SF-36 health survey manual and interpretation guide. Boston: New England Medical Center; 1993.

10. Brooks R. Quality of life measures. Crit Care Med. 1996;24:1769.

11. Smets EM, Garssen B, Bonke B, De Haes JC. The Multidimensional Fatigue Inventory (MFI) psychometric qualities of an instrument to assess fatigue. J Psychosom Res. 1995;39:315-25.

12. Gehi AK, Sears S, Goli N, Walker TJ, Chung E, Schwartz J, et al. Psychopathology and symptoms of atrial fibrillation: implications for therapy. J Cardiovasc Electrophysiol. 2012;23(5):473-8.

13. Dabrowski R, Smolis-Bak E, Kowalik I, Kazimierska B, Wojcicka M, Szwed H. Quality of life and depression in patients with different patterns of atrial fibrillation. Kardiol Pol. 2010;68:1133-9.

14. Thrall G, Lip GY, Carroll D, Lane D. Depression, anxiety, and quality of life in patients with atrial fibrillation. Chest. 2007;132:1259-64.

15. Ong L, Cribbie R, Harris L, Dorian P, Newman D, Mangat I, et al. Psychological correlates of quality of life in atrial fibrillation. Qual Life Res. 2006:15:1323-33.

16. Ong L, Irvine J, Nolan R, Cribbie R, Harris L, Newman D, et al. Gender differences and quality of life in atrial fibrillation: The mediating role of depression. J Psychosom Res. 2006;61:769-74. 
17. Eaker ED, Sullivan LM, Kelly-Hayes M, D'Agostino RBS, Benjamin EJ. Tension and anxiety and the prediction of the 10-year incidence of coronary heart disease, atrial fibrillation, and total mortality: the Framingham Offspring Study. Psychosom Med. 2005;67:692-6.

18. Frasure-Smith N, Lesperance F, Habra M, Talajic M, Khairy P, Dorian P, Roy D. Elevated depression symptoms predict long-term cardiovascular mortality in patients with atrial fibrillation and heart failure. Circulation. 2009;120:134-40.

19. Lange HW, Herrmann-Lingen C. Depressive symptoms predict recurrence of atrial fibrillation after cardioversion. J Psychosom Res. 2007;63:509-13.

20. Tully PJ, Bennetts JS, Baker RA, McGavigan AD, Turnbull DA, Winefield HR. Anxiety, depression, and stress as risk factors for atrial fibrillation after cardiac surgery. Heart Lung. 2011;40:4-11.

21. Raine D, Langley P, Shepherd E, Lord S, Murray S, Murray A, Bourke JP. Effect of catheter ablation on quality of life in patients with atrial fibrillation and its correlation with arrhythmia outcome. Open Heart. 2015;2(1):e000302.

22. Jais P, Cauchemez B, Macle LR, Daoud E, Khairy P, Subbiah R, et al. Catheter ablation versus antiarrhythmic drugs for atrial fibrillation: the A4 study. Circulation. 2008;1 18:2498-505.

23. Wokhlu A, Monahan KH, Hodge DO, Asivatham SJ, Friedman PA, Munger TM, et al. Long-term quality of life after ablation of atrial fibrillation: the impact of recurrence, symptom relief, and placebo effect. J Am Coll Cardiol. 2010:55:2309-16

24. Fiala M, Wichterle D, Bulková V, Sknouril L, Nevralová R, Toman O, et al. A prospective evaluation of haemodynamics, functional status, and quality of life after radiofrequency catheter ablation of long-standing persistent atrial fibrillation. Europace. 2014;16(1):15-25.

25. Haegeli LM, Duru F, Lockwood EE, Lüscher TF, Sterns LD, Novak PG, Leather RA.J. Ablation of atrial fibrillation after the retirement age: considerations on safety and outcome. Interv Card Electrophysiol. 2010;28(3):193-7.

\section{Submit your next manuscript to BioMed Central and we will help you at every step:}

- We accept pre-submission inquiries

- Our selector tool helps you to find the most relevant journal

- We provide round the clock customer support

- Convenient online submission

- Thorough peer review

- Inclusion in PubMed and all major indexing services

- Maximum visibility for your research

Submit your manuscript at www.biomedcentral.com/submit 